\title{
Abnormal technetium labelled white cell scan in the colitis of chronic granulomatous disease
}

\author{
S Hoare, J E Walsh, E Eastham, M A Abinun, A J Cant
}

\begin{abstract}
A child with colitis was treated for Crohn's disease, diagnosed on history, clinical and colonoscopic findings, radiolabelled white cell bowel scan, and colonic histology. After septicaemia caused by an unusual organism, further investigation lead to a diagnosis of chronic granulomatous disease (CGD). The granulomatous colitis of CGD is clinically, histologically, and on white cell scanning, indistinguishable from that in Crohn's disease and should be considered in atypical cases. Infection with unusual 'pseudomonads' should prompt the exclusion of this disorder. (Arch Dis Child 1997;77:50-51)
\end{abstract}

Keywords: chronic granulomatous disease; colitis; Crohn's disease

Colitis with anal fissures and skin tags is unusual in childhood and suggests inflammatory bowel disease. Although colonic disease is more often associated with ulcerative colitis, Crohn's disease can occur anywhere within the gastrointestinal tract. The diagnostic 'gold standard' for Crohn's disease is histology, supported by clinical, contrast radiography, and endoscopic findings. Recently the role of the technetium-99m HMPAO labelled white cell scan (Tc-WCS) in the investigation of inflammatory bowel disease in children has been emphasised. ${ }^{1}$ We report a child in whom clinical, Tc-WCS, endoscopic, and histological features all suggested Crohn's disease but who, after a septicaemia with a novel infectious agent, was found to have chronic granulomatous disease (CGD).

\section{Case report}

An 5 year old boy presented with a two year history of abdominal pain, rectal bleeding, and loose stools. He had an epididymitis at 5 months of age, a neck abscess when 18 months, and an empyema at the age of 19 months. His height was on the 10th centile and weight on the 50th. There was marked perianal erythema and induration, with two large anal skin tags. Full blood count, urea and electrolytes, and liver function tests were normal; erythrocyte sedimentation rate was $12 \mathrm{~mm} /$ hour. Multiple stool cultures were negative. A Tc-WCS showed increased uptake in the ascending colon. Sigmoidoscopy showed granular rectal mucosa with contact bleeding, and a biopsy specimen showed a marked increase in chronic inflammatory cells within the lamina propria extending into the muscularis mucosa. There were well formed granulomas within the lymphoid follicles. These findings were considered to be consistent with Crohn's disease, and he was started on oral prednisolone (2 $\mathrm{mg} / \mathrm{kg} /$ day). When reviewed one month later he was significantly better; the steroid dosage was gradually reduced, and mesalazine added.

Three months later he had a three week period of general malaise and intermittent fever. After three weeks he deteriorated, with a swinging pyrexia and multiple painful skin lesions. He was cushingoid, flushed, and ill with a temperature of $40.5^{\circ} \mathrm{C}$. There was a scar from the previous neck abscess, and he had many haemorrhagic/necrotic pustules varying in size from $3 \mathrm{~mm}$ to $3 \mathrm{~cm}$. His abdomen was distended and he had hepatosplenomegaly. Blood and pustule fluid cultures grew a 'pseudomonad', which was identified by the National Collection of Type Cultures Laboratory (Colindale, London) as Pseudomonas gladioli, subsequently renamed Burkholderia gladioli. The haemoglobin was $101 \mathrm{~g} / 1$, white cell count $3.8 \times 10^{9} / 1$ (neutrophils 2.5 , lymphocytes 1.2 ), platelets $79 \times 10^{9} / 1$. Fibrinogen was high at 5.1 $\mathrm{g} / \mathrm{l}$, and clotting times deranged with an international normalised ratio of 1.8 and an activated partial thromboplastin ratio of 1.6. Liver function tests showed an albumin of 18 $\mathrm{g} / 1$ with an alanine transaminase of $73 \mathrm{U} / 1$. C reactive protein was $101 \mathrm{mg} / \mathrm{l}$. Immunoglobulins were raised (IgG 16.3, IgA 4.6, IgM 3.9 $\mathrm{g} / \mathrm{l})$. The nitroblue tetrazolium test showed no reduction of dye, confirming a diagnosis of CGD.

$\mathrm{He}$ was treated with intravenous ciprofloxacin, gentamicin, and itraconazole. Interferon gamma was given subcutaneously for two months ( $50 \mu \mathrm{g} / \mathrm{m}^{2}$, three times per week). Stress doses of steroids were given acutely but were reduced and subsequently stopped. $\mathrm{He}$ improved steadily over the following weeks; for the first time in two years he had normal stools. Prophylactic treatment with co-trimoxazole and itraconazole continues.

\section{Discussion}

The association between colitis and CGD has been previously described. ${ }^{2}$ This child had a colitis with many typical clinical features of Crohn's disease with supportive findings on Tc-WCS. In an evaluation of different methods of examination of the bowel in suspected inflammatory bowel disease in children a wide range of disorders (including all those patients with Crohn's disease) were associated with abnormal white cell scans, ${ }^{1}$ but we believe that 
this is the first time Tc-WCS abnormality has been noted in CGD associated colitis.

Histologically Crohn's disease is characterised by transmural inflammation with the formation of small non-caseating granulomas, but again there are no distinguishing microscopic features between Crohn's disease and CGD. ${ }^{3}$ Retrospectively, many of the granuloma were found adjacent to or within lymphoid follicles, as noted previously by Ament and Ochs. ${ }^{2}$

A definite improvement on steroids and mesalazine was noted presumably related to their anti-inflammatory effects. However in the presence of a primary immunodeficiency the inadvertent use of steroids is likely to be hazardous, stressing the importance of early diagnosis.

It seems unlikely that any other methods of investigation would have distinguished between the colitis of Crohn's disease and CGD, and we emphasise the importance of a high index of suspicion for the further investigation of colitic children with previous multiple invasive infections or sepsis with unusual organisms. CGD is a life threatening primary immunodeficiency characterised by recurrent suppurative infections, fungal sepsis, granuloma formation, and an abnormal oxidative burst leading to suboptimal reduction of dye in the nitroblue tetrazolium test. Early detection is important as effective treatment for CGD now exists. While acute management depends upon prompt recognition and treatment of current infection, debate continues regarding long term therapy; in accord with European guidelines our patient had cytokine treatment acutely and lifelong fungal and bacterial prophylaxis. ${ }^{4}$

Burkholderia (formerly Pseudomonas) gladioli is a Gram negative, catalase positive aerobic bacillus which resembles but is distinct from Burkholderia (Pseudomonas) cepacia, a pathogen well described in both cystic fibrosis and CGD. We have previously reported the isolation of this organism ${ }^{5}$ and Ross et al have reported two successfully treated cases in adults with CGD. ${ }^{6}$

CGD is an unusual cause of colitis, and may be indistinguishable clinically, on white cell scan, and histologically from Crohn's disease; where doubt exists a nitroblue tetrazolium test, which is cheap, rapid and easy to perform, should be done. In overwhelming sepsis with CGD, early intervention with a combination of antimicrobials and immunotherapy may prove life saving. Burkholderia gladioli should be added to the already long list of pathogens found in this condition.

1 Jobling JC, Lindley KJ, Yousef Y, Gordon I, Milla PJ. Investigating inflammatory bowel disease-white cell scanning, radiology, and colonoscopy. Arch Dis Child 1996;74:22-6.

radiology, and colonoscopy. Arch Dis Child 1996;74:22-6.
2 Ament ME, Ochs HD. Gastrointestinal manifestations of Ament ME, Ochs HD. Gastrointestinal manifestations of
chronic granulomatous disease. $N$ Engl f Med 1973;288: chronic

3 Isaacs D, Wright VM, Shaw DG, Raafat F, Walker-Smith JA. Chronic granulomatous disease mimicking Crohn's disease. F Pediatr Gastroenterol Nutr 1985;4:498-501.

4 Fischer A, Segal AW, Seger R, Weening RS. The management of chronic granulomatous disease. Eur f Pediatr 1993;152896-9.

5 Hoare S, Cant AJ. Chronic granulomatous disease presenting as severe sepsis due to Burkholderia gladioli. Clin Infect Dis 1996;23:411.

6 Ross JP, Holland SM, Gill VJ, DeCarlo ES, Gallin JI. Severe Burkholderia (Pseudomonas) gladioli infection in chronic granulomatous disease: report of two successfully treated cases. Clin Infect Dis 1995;21:1291-3. 